\title{
THE RELATIONSHIP OF HISTAMINE AND THE INTRA-OCULAR PRESSURE
}

BY

\author{
B. W. RYCROFT \\ LONDON
}

IN the pathogenesis of acute glaucoma there are two factors, one of which is of pre-disposition, the other of immediate excitation. The pre-disposing factors have long been known and include variations in scleral distensibility, increasing lens volume, and changes at the angle of the anterior chamber, but the actual exciting causes, which precipitate an acute attack of glaucoma, are less understood and are intimately related to the nervous control of the ocular capillaries and the disturbance of intra-ocular osmotic equilibrium ; for the dominant note of acute glaucoma is essentially one of vascular strangulation in which a sudden uveal engorgement is grafted on to an eye made previously susceptible to it by structural alterations.

The purpose of this paper is to investigate possible immediate causes of this vascular disturbance and to correlate laboratory findings with clinical cases.

\section{Theme}

Duke-Elder has drawn attention to the close parallelism which exists between the reactions of the iris and the skin to local injury. He identifies the triple response of Lewis in the case of the iris as follows :-(1) Local dilatation of minute vessels which is comparable to the red streak on the skin. (2) An increased impermeability of the capillary walls, comparable to the wheal. (3) Widespread dilatation of the arterioles, comparable to the flare. But in addition to visible effects the disturbance of capillary permeability causes a rise in intra-ocular pressure. The effect on the size and permeability of the minute vessels appears to be due to the local liberation of an " $\mathrm{H}$ substance" in the tissues (vide infra), whilst the flare is dependent on the continuity of a reflex arc of the axon type, since it does not occur after cocainization. In the normal eye, therefore, it is possible by local intrinsic mechanism to bring about a rise of pressure chiefly by reflex disturbance of osmotic equilibrium and vascular engorgement; if this should occur in an eye in which the compensatory mechanism of decompression was faulty then the pressure would rise still higher and a condition of acute glaucoma be brought about. The problems which seemed to require investigation were:-(1) The effect of histamine on the intra-ocular pressure of the normal eye. (2) The identification of histamine in the aqueous in cases of acute glaucoma. 


\section{Histamine}

(A) General properties.-Investigations of histamine commenced by the formation of an active amine by decarboxylation from the amino-acid histidine and were essetially pharmacological; later, the relationship of wound-shock in men and peripheral vasodilatation in animals came to be studied, culminating in the discovery of the part which the substance plays in skin reactions. For clinical purposes it was essential to use a method of detection which was rapid, sensitive and applicable in the ward, as decomposition of histamine takes place relatively quickly. It was, therefore, decided to use the intra-cutaneous injection and the production of a subsequent flare as the test, after the method of Harris, for although the Knoop colour reaction and methods of biological assay as used by Burn and Dale are eminently satisfactory in laboratory practice, they do not lend themselves to clinical methods of investigation. The general effects of histamine are as follows :-

(1) On the salivary glands.- There is an increased production of saliva which is partly due to chorda stimulation and partly to the mechanical effect of smooth muscle contraction (MacKay, 1927).

(2) On the stomach.- Histamine acts as a stimulant to the acid producing cells but has less effect on the peptic and mucoid cells, the net result being a rise in the volume of the gastric juice(Dobson, 1925 and Babkin, 1930).

(3) On the blood vessels. - Intra-venous injection produces a profound lowering of the blood pressure in the anaesthetized cat (Dale and Laidlaw, 1910). This is due to a wide-spread peripheral vaso-dilatation.

(4) On the skin.- In the human skin the arterioles are widely dilated (Harmer and Harris, 1926); Carrier has described the intense capillary dilatation in the finger nail bed. Lewis has described the triple response, which has been mentioned previously, and suggests, in view of the prolonged effects resulting from injury to the skin, that these are produced by a substance not identically the same as histamine, since this is so readily diffusible. but to an unknown substance related to it which he has termed "H substance." Dale has suggested that histamine is liberated from the cells locally and is mainly responsible for the effects on the skin, but that it is modified to $\mathrm{H}$ substance by loose combination. Krogh believes that a vaso-toxic substance is liberated from the cells but that it is composed of several components; acetyl-cholin has been suggested by Dudley as being one of them.

(5) Smooth muscles. - All authorities agree that there is stimulation and contraction of smooth muscle, a fact which is of advantage for the method of assay by the guinea-pig uterus. 
(B) The eye.-In 1910, Dale and Laidlaw reported no change in the size of the pupil after intra-venous injection of histamine. Hamburger later found that instillation into the conjunctival sac produced miosis. Studying the effects on different animals Matsuda has described varying effects on the pupil: in cats no effect was found on the pupil after subconjunctival injection. Colle and Duke-Elder have shown that the intra-venous injection of histamine produces a rise of intra-ocular pressure provided that the tone of the capillaries generally was well maintained. Friedenwald and Pierce, using various animals, described the effects of injection of histamine into the anterior chamber and vitreous with subsequent histological results. They found that when intra-ocular pressure was kept constant, injection of histamine into the anterior chamber produced a rise of intra-ocular pressure, followed by massive congestion and oedema of the eye ; into the vitreous, a more prolonged rise was produced. Dubar and Labache emphasize the variability of the results and this appears to be a current note in the literature; Dale has stressed such variations as the genealogical tree is ascended. It follows, therefore, that strict adherence to animal experimental results cannot be maintained.

\section{Experimental Evidence}

For the purpose of these experiments the technique followed was mainly that of Duke-Elder in which intra-ocular readings are taken by an optical manometer co-incidentally with a record of the general blood pressure. A modification was introduced in order to maintain the intra-ocular pressure constant whilst histamine was injected; this was brought about by means of reciprocating syringes acting as a shunt. Cats were employed under chloroform-ether induction, followed by light intra-venous chloralose. Blood pressure record was taken from the left carotid. In some experiments where gross changes were expected a saline manometer was employed (Fig. 1).

(1) Conjunctiva.-On instilling two drops of $1 / 1,000,000$ histamine solution into the conjunctival. sac there was a latent period of about four minutes, followed by a period of capillary dilatation, lasting about 10 minutes, in which the whole of the conjunctiva became red and congested. No constant action on the pupil was observed. With stronger solutions miosis was produced and in some cases marked irregularity of the blood pressure which was brought about by absorption. This may have some bearing on the general effects which certain patients experience after the use of preparations of concentrated histamine for the production of miosis (Fig. 2). 
(2) Anterior chamber.-Injection of saline into the anterior chamber with no reciprocating mechanism produced a rise of intra-ocular pressure, but if an equal volume of histamine and saline was injected a similar rise of intra-ocular pressure was

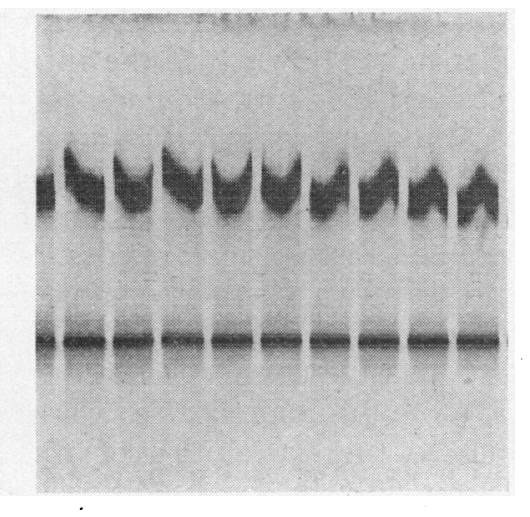

FIG. 1.

Normal tracing of intra-ocular pressure (cat), taken by optical manometer. The large waves are of respiration : the small waves are cardiac. Base-line photographed from fixed mirror. Time-marker: 5 sec. blank.

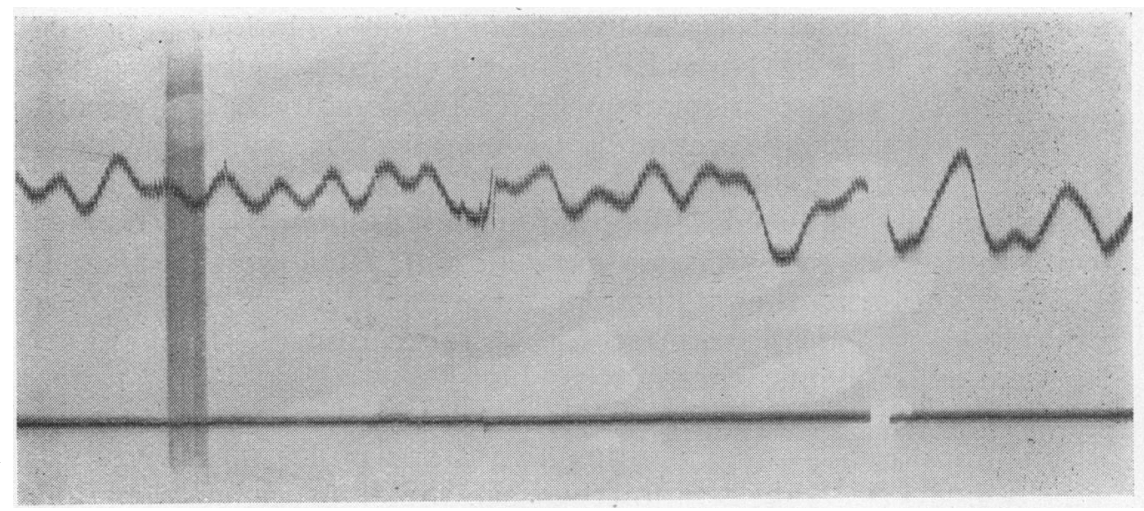

FIG. 2.

At signal, the conjunctival sacs of both eyes were flooded with 1:1000 solution histamine. Thereafter, there was marked irregularity of intra-ocular and blood pressures (cat).

produced, followed almost immediately by a further subsequent rise which was due to the effect of histamine. With the reciprocating mechanism in use injection of histamine alone produced a rise of intra-ocular pressure. The general blood pressure was found to vary and no constant fall produced (Fig. 3). 


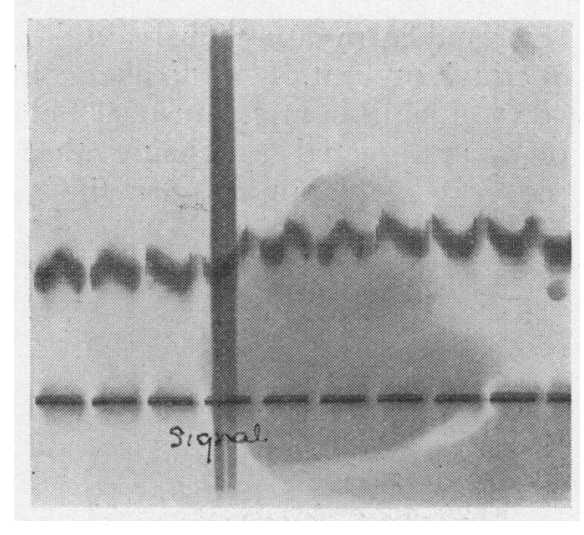

FIG. 3.

Fig. 3 shows rise of intra-ocular pressure following injection of histamine into aqueous. At signal, 0.3 of 1:10,000 histamine solution was injected into the anterior chamber of a cat, the intraocular pressure being kept constant during injection.

(3) Vitreous.-Injection of histamine into the vitreous was in all cases followed by a sharp and well-maintained rise of intraocular pressure, subsequently followed by a gradual fall.

(4) Blood stream.-Intra-venous injections confirmed the work of previous observers, namely that if the capillary tone generally is good the fall of general blood pressure produces a rise of intraocular pressure due to local capillary dilatation and increased permeability. In very prolonged deep anaesthesia the capillaries are partly atonic. These effects are not constant and the rise of intra-ocular pressure may be replaced by a fall (Fig. 4).

\section{Clinical Evidence}

In these experiments an endeavour was made to correlate the experimental results with clinical cases of acute glaucoma and to identify histamine or "H substance" in the aqueous of these cases. Four cases of primary acute glaucoma were selected all having tonometric tension of over $\pi 0 \mathrm{~mm}$. of mercury, and uncomplicated by previous operation or miotic treatment. All cases of primary glaucoma do not lend themselves to these experiments since it must be possible to extract aqueous without risk of gross damage; this postulates an anterior chamber which is not too shallow and accordingly cases have to be selected. Two control cases of primary optic atrophy were employed. The technique of the experiments was to tap the anterior chamber obliquely with a fine bore hypodermic needle and to withdraw 0.2 c.c. of aqueous. Retrobulbar and sub-Tenon anaesthesia were employed and no 
part of the conjunctiva was penetrated. The aqueous thus obtained was immediately injected intra-cutaneously into the flexor surface of the forearm; an equal amount of saline as a control was injected alongside. Next day, a similar injection of $0 * 2$ c.c. of $1 / 1,000,000$ histamine solution was injected to ensure that all cases were sensitive to the presence of histamine. In the two control cases

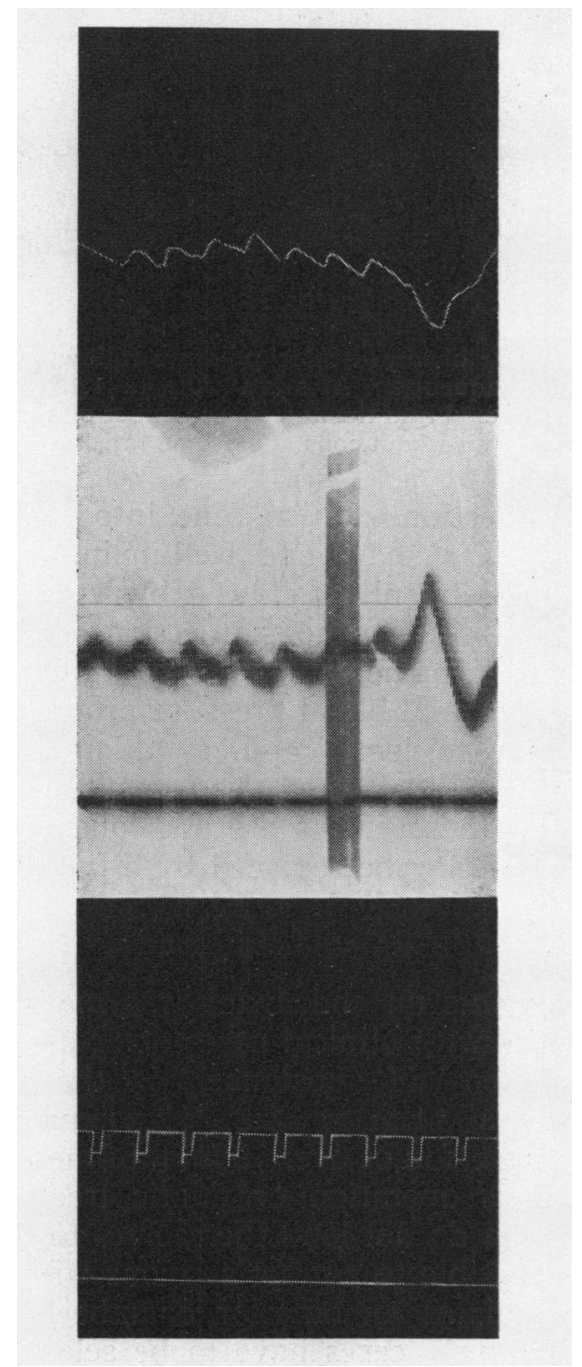

FIG. 4.

Fig. 4 shows synchronous fall of systemic blood-pressure and rise of intra-ocular pressure. At signal, 03 of $1: 1,000,000$ solution histamine was injected into the left femoral vein. Cat : ether and chloralose. 
of optic atrophy no reaction was obtained by the injection of aqueous or saline; the histamine injection gave a flare in both cases. In three of the four cases of primary glaucoma a small but definite flare was produced. In one case no flare was obtained, and in none was there a wheal. Friedenwald has carried out similar experiments on the relationship of histamine to acute glaucoma and the intra-ocular pressure. He states that the injection of histamine into the vitreous produces histologically changes in the ciliary body and processes similar to those found in acute glaucoma in man. The lesion, however, is less severe than that in human beings. In no case was obstruction of the filtration angle produced. The author has had similar experiences and found that it is impossible to produce a permanent obstruction at the angle of the anterior chamber by these injections into animals, the reason being that the ciliary body is small and the anterior chamber usually deep. Friedenwald carried out further investigations by injecting glaucomatous aqueous into the skin in one case ; in this case he obtained a wheal measuring $7.5 \mathrm{~mm}$. 17 minutes after injection. This, however, was obtained from an eye in which an iridectomy had been performed nine days previously and, therefore, the presence of histamine from the operation cannot entirely be excluded. Control aqueous from the conjunctival sac during extraction of a senile cataract was used but this can hardly have been free from contamination. He concludes that a vaso-toxic substance is present in the aqueous in glaucoma which is capable of producing an urticarial wheal elsewhere in the same patient. The author has never been able to produce a wheal although using a larger quantity of aqueous than this observer.

\section{Conclusions}

(1) That the effect of histamine on animal eyes varies according to species.

(2) That the injection of histamine into the eye of a cat will produce per se a rise of intra-ocular pressure independent of that due to its own volume.

(3) That a vaso-toxic substance is present in the aqueous in cases of acute glaucoma but that at the moment its nature is indeterminate; it is possibly " $\mathrm{H}$ substance" or is related to it.

It is proposed to extend the clinical evidence further as no final conclusion can be based on three positive cases and to investigate the parallel effects of acetyl choline which may also play a part.

My thanks are due to Sir Stewart Duke-Elder for his constant interest and advice, to Professor Lovatt Evans for many courtesies 
and to the Medical Research Council for their kindness in defraying the expense of the animal experimentation.

\section{BIBLIOGRAPHY}

Babkin, B. P., and M. E. MacKay.-Amer Jl. of Physiol., Vol. XCI, p. 370, 1930.

Best, C. H. and E. W. McHenry.-Phys Rev., Vol. XI, No. 4, Oct., 1931.

Burn, J. H.-Methods of Biological Assay. Oxford Univ. Press, 1928.

Carrier, E. B -Amer. Jl. of Physiol., Vol. LXI, p. 528, 1922.

Colle, J., P. M. Duke-Elder and W. S. Duke-Elder.-Jl. of Physiol., Vol. LXXI, p. 1, 1931.

Dale, H. H.-Lancet, Vol. I, pp. 1179, 1233, 1285, 1929.

Dale, H. H., and H. W. Dudley.-Jl. of Physiol., Vol. LXVIII, p. 97, 1929.

Dale, H. H., and P. P. Laidlaw.- Jl. of Physiol., Vol. XLI, p. 318, 1910.

Dale, H. H., and P. P. Laidlaw.-Jl. of Pharm. Exper. Therap., Vol. IV, p. 75, 1912.

Dobson, H. V.-Jl. Amer. Med. Assoc., Vol. LXXXIV, p. 158, 1925.

Dubar, J., and Lamache, A.-Bull. Soc. d'ophtal. de Paris, Vol. XLI, pp. 421-3, 1929.

Duke-Elder.-Proc. Roy. Soc., Vol. CIX, pp. 612, 842, 1931.

Friedenwald and Pierce.-Arch. of Ophthal., Vol. III, No. 5, 1930.

Gautier, C.-Compt. rend. Soc. de Biol., 1927.

Hadjimichalis.-Arch. f. exp. Path. u. Pharm., Vol. CLX, pp. 49, 52, 1931.

Hamburger, C.-Klin. Wochenschr., v. 2114, 1926; Klin. Monatsbl.f. Augenheilk., Vol. LXXVI, p. 849, 1926.

Harmer, I. M., and K. E. Harris.-Heart, Vol. XIII, p. 381, 1926.

Harris, K. E-Heart, Vol. XIV, p. 161, 1927.

Knoop, F.-Beit. z. Chem. Physiol. u. Path., Vol. XI, p. 356.

Krogh, A.-Anat. and Physiol. of the capillaries. Yale University Press, 1929.

Lewis, T.-The blood vessels of the human skin and their responses. 1927.

MacKay, M. E.-Amer. Jl. of Physiol., Vol. LXXXII, p. 546, 1927.

Matsuda, A.-Arch. f. exp. Path. u. Pharm., Vol. CXLII, pp. 70-74, 1929.

\section{RICHARD BANISTER \\ Additional facts in relation to the Father of British Ophthalmology}

BY

\section{R. R. James ANd ARNold Sorsby}

\section{LONDON}

SloAne MS. 3801 in the British Museum, published in full in "Studies in the History of Ophthalmology in England prior to 1800 " is of importance because of the wealth of detail about itinerant oculists in the early part of the XVIIth century. It is an anonymous, undated tract which ends abruptly in the middle of autobiographical details concerning its writer. The Museum authorities dated it in the time of Charles the First, and Mr. Harvey Bloom judged its date to be between 1630 and 1640 . The writer speaks of himself as an oculist and mentions his brothers Gabriel and John. He also states that he was trained by his uncle, the author of a "booke of Anathomy." Because of 